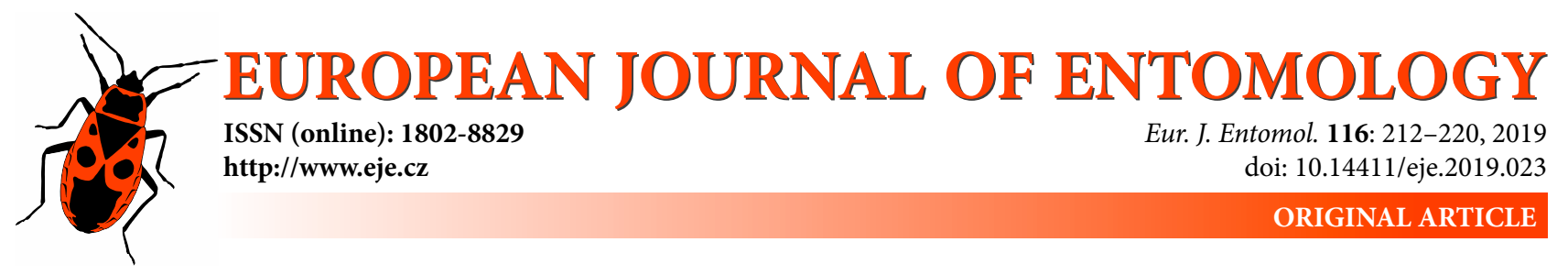

\title{
The maternal effects of heat shock on biological parameters and ovaries of Frankliniella occidentalis (Thysanoptera: Thripidae)
}

\author{
Lijuan SUN ${ }^{1}$, Yabin MA ${ }^{1}$, Honggang LI $^{2}$ and Changying ZHENG ${ }^{1, \text { * }}$ \\ ${ }^{1}$ Key Laboratory of Integrated Crop Pest Management of Shandong Province, College of Agronomy and Plant Protection, \\ Qingdao Agricultural University, 700 of Changcheng Road, Chengyang District, Qingdao City, Shandong Province, 266109, \\ China; e-mails: sunlj12@163.com,15006587071@163.com, zhengcy67@qau.edu.cn \\ 2 Plant Protection Station of Shandong Province, Jinan, Shandong Province, China; e-mail: Ixfbxc@sina.com
}

Key words. Thysanoptera, Thripidae, Frankliniella occidentalis, double heat shock, fertility, longevity, maternal effect, ovary, sex ratio, single heat shock, survival

\begin{abstract}
Maternal effects of heat shock are reported for some species of insects, but little is known about such effects in the western flower thrips (WFT) Frankliniella occidentalis (Pergande) (Thysanoptera: Thripidae). WFT is a pest of vegetables in greenhouses worldwide. It is susceptible to high temperatures in its natural environment and is controlled using heat treatment in China. WFT population growth is suppressed by a brief exposure to a high temperature of $40^{\circ} \mathrm{C}$ or $45^{\circ} \mathrm{C}$ in the laboratory. To explore the mechanism by which high temperatures suppress the growth of WFT populations, as well as the effects of multiple heat treatments on WFT, we recorded the duration of development and survival of immature WFT, and the sex ratio (female/male) and fecundity of $F_{1}, F_{2}, F_{3}$ and $F_{4}$ adult females that developed after a single heat shock, and those of $F_{2}$ offspring after a double heat shock. We also recorded the longevity and ovarian structure of adult females of the treated generation $(P)$ and their $F_{1}, F_{2}$ and $\mathrm{F}_{3}$ offspring after a single heat shock. In addition, we determined whether the effects of a heat shock on second instar nymphs and adults differed. The results indicate that exposure of the parental generation to $41^{\circ} \mathrm{C}$ or $45^{\circ} \mathrm{C}$ for $2 \mathrm{~h}$ significantly prolonged the duration of development, reduced survival of immature WFT and altered the sex ratio (female/male), longevity and fertility of their adult female offspring. The effects of a heat shock of $41^{\circ} \mathrm{C}$ persisted for two generations, whilst the effect of heat shock of $45^{\circ} \mathrm{C}$ persisted for three generations. In addition, double heat shocks had more pronounced effects than a single heat shock. Heat shock administered to second instar nymphs resulted in a decrease in the number of ovarioles, whilst a heat shock administered to adults resulted in ovariole deformity. The maternal effects of heat shock in terms of the biological parameters of WFT, structure and number of ovarioles, are critical in determining the suppression of the growth at high temperatures of WFT populations.
\end{abstract}

\section{INTRODUCTION}

Maternal effects of environmental factors are reported not only for plants (Roach \& Wulff, 1987) but also insects (Crill et al., 1996; Chen et al., 2011). For example, the effects of heat shock persist to the next generation if the treated insects are not killed (Denlinger \& Yocum, 1998). Maternal heat stress leads to a clear decrease in the body mass, rate of development and reproduction in progeny of Aphis pomi (de Geer) (Carroll \& Hoyt, 1986). Thermal injury to the parental generation affects the population size of Drosophila melanogaster Meigen for at least two generations (Crill et al., 1996) and lowers the total percentage survival of immature western flower thrips (WFT) and the sex ratio (female/male) of the $\mathrm{F}_{1}$ generation of Bemisia tabaci (Gennadius) Q-biotype (Cui et al., 2008, 2011). In addition, as a result of heat stress, the parthenogenetic Dros- ophila mercatorum produces offspring the wings of which differ in size and shape (Andersen et al., 2005).

The WFT, Frankliniella occidentalis (Pergande) (Thysanoptera: Thripidae), is a destructive pest that severely damages crops by feeding, egg-laying and spreading plant viruses (Kirk \& Terry, 2003). WFT are native to North America and have spread to nearly 70 countries on all continents except Antarctica (Van Rijna et al., 1995). This insect pest has caused severe damage to vegetables in greenhouses in Beijing, China since 2003 (Zhang et al., 2003) and has recently spread to Shandong Province (Zheng et al., 2007). This pest is susceptible to high temperatures in its natural environment and is controlled using heat treatment in China. WFT population growth is suppressed by a brief high temperature treatment of $41^{\circ} \mathrm{C}$ or $45^{\circ} \mathrm{C}$ in the laboratory (Zhang et al., 2009; Wang et al., 2014a, b; Jiang et al., 2016). We suspected that the effect of heat treatment

\footnotetext{
* Corresponding author; e-mail: zhengcy67@qau.edu.cn
} 
can also affect subsequent generations. In Shandong Province in China, brief exposures to temperatures above $45^{\circ} \mathrm{C}$ can occur in greenhouses starting in May; thus, at least two generations of WFT encounter high temperatures in greenhouses. We also wondered whether a double heat shock (experienced by both parental and $\mathrm{F}_{1}$ generations) might have different effects from those of a single heat shock (only on parental generations). In this paper, we investigated the effects of subjecting the parents to a heat shock on the duration of development and survival of the immatures, the sex ratio and the fecundity of adult females of the first $\left(\mathrm{F}_{1}\right)$, second $\left(\mathrm{F}_{2}\right)$, third $\left(\mathrm{F}_{3}\right)$ and fourth $\left(\mathrm{F}_{4}\right)$ generation offspring, and the longevity and structures of the ovaries of the females in the treated generation $(\mathrm{P})$ and their $\mathrm{F}_{1}, \mathrm{~F}_{2}$ and $\mathrm{F}_{3}$ offspring. The results of this study may improve our understanding of the mechanism by which high temperatures suppress the growth of WFT populations.

\section{MATERIALS AND METHODS}

\section{Insects and host plants}

The WFT, F. occidentalis, used in this study were originally collected from clover (Trifolium repens L.; Fabales: Fabaceae) at the Experimental Station of Qingdao Agricultural University in June 2007. The colony was maintained on leaves of purple cabbage (Brassica oleracea L.) in glass bottles $(1500 \mathrm{~mL})$ in an incubator under standard conditions $\left(25 \pm 2^{\circ} \mathrm{C}\right.$, relative humidity of $55 \pm 5 \%$ and a $16 \mathrm{~L}: 8 \mathrm{D}$ daily cycle).

\section{Experiments}

Effects of subjecting adults to a single heat shock on the biological parameters of their offspring

One hundred 1-day-old adults (50 females and 50 males) cultured in bottles under standard conditions were exposed to a high temperature $\left(41\right.$ or $\left.45^{\circ} \mathrm{C}\right)$ for $2 \mathrm{~h}$ in an incubator. Twenty female and 20 male survivors that were actively moving were randomly selected and paired for mating. Each pair was placed in a centrifuge tube $(100 \mathrm{ml})$ and provided with a piece of purple cabbage leaf under standard conditions. Twenty females and 20 males that were not subjected to a heat shock were maintained as controls. If males died during an experiment they were replaced by new similarly treated males. The purple cabbage leaf in each tube was collected daily and a piece was supplied as food and an egg laying substrate. The leaf collected from each tube was transferred to a Petri dish kept under the same standard conditions and the number of nymphs that hatched was recorded every $24 \mathrm{~h}$. When first instar nymphs of the $F_{1}$ generation hatched, five 1-day-old individuals that hatched within a day were randomly selected from each pair (100 in total). Each nymph was reared on a piece of purple cabbage leaf in a tube kept under the same standard conditions. The nymph was transferred to a new tube containing a piece of leaf every 3 days. The survival and duration of developmental of immature WFT (from first instar nymph to pseudo pupa) were recorded (Jiang et al., 2014). All the offspring from 20 pairs that were not used to determine survival and duration of development were maintained in bottles (ca. 90-100 individuals per bottle, with new food supplied every 3 days) under standard conditions until the adults emerged when the sex ratio was recorded. Twenty females and 20 males of the $F_{1}$ generation that emerged on the same day were randomly collected from all the progenies of 20 pairs and paired to produce the next generation. The purple cabbage leaf in each tube was collected daily after pairing and was transferred to a Petri dish, and the number of nymphs that hatched under standard conditions was recorded every $24 \mathrm{~h}$ until no newly hatched nymphs were found. The total number of newly hatched nymphs (that is, hatched eggs) was recorded as the fecundity of the pair. The survival of females was also monitored every $24 \mathrm{~h}$ until all the females died. In this way, the population was maintained until all the nymphs of $\mathrm{F}_{5}$ hatched, and for each offspring generation, the duration of development and survival of immature WFT, the sex ratio (female/male), and the female longevity and fecundity were recorded. The population cultured under standard conditions was used as a control (Fig. S1). The experiments involving heat treatment of the parental generation and examination of $\mathrm{F}_{1}, \mathrm{~F}_{2}, \mathrm{~F}_{3}$ and $\mathrm{F}_{4}$ were replicated three times.

Effects of subjecting nymphs to a single heat shock on the biological parameters of their offspring

Experiments and rearing were conducted as described above, except thet heat shock was applied to second instar nymphs (Fig. S2).

Effects of subjecting adults to a double heat shock on the biological parameters of their offspring

One hundred 1-day-old adults (50 females and 50 males) cultured in a bottle under standard conditions were exposed to a high temperature $\left(41\right.$ or $\left.45^{\circ} \mathrm{C}\right)$ for $2 \mathrm{~h}$ as described above. Twenty female and 20 male survivors were paired, and each pair was placed in a tube to produce the $F_{1}$ generation. Twenty pairs that were not subjected to a heat shock were maintained as a control. The purple cabbage leaf in each tube was collected daily as described above and used to determine the number of nymphs that hatched. When first instar nymphs of the $\mathrm{F}_{1}$ generation hatched, they were reared on purple cabbage leaves in bottles (ca. 90-100 individuals per bottle, with new food supplied every 3 days) under standard conditions. When the adults of the $\mathrm{F}_{1}$ generation emerged, 100 1-day-old individuals ( 50 females and 50 males) that emerged on the same day were randomly collected and exposed again to 41 or $45^{\circ} \mathrm{C}$ for $2 \mathrm{~h}$. Twenty females and 20 males that survived the heat shock were randomly collected from the treated group and control group, respectively, and paired. Each pair was placed in a tube and cultured under standard conditions to produce the $\mathrm{F}_{2}$ generation. When first instar nymphs of the $\mathrm{F}_{2}$ generation hatched, they were treated in the same way as in the single-heat-shock experiment. The only difference was that the population was maintained until all the nymphs of the $\mathrm{F}_{3}$ generation hatched. The biological parameters, including duration of development, survival of immature WFT, sex ratio, female longevity and fecundity $(\mathrm{N}=20)$, were recorded (Fig. S3). The experiments involving heat treatment of the parental generation and examination of $F_{1}, F_{2}, F_{3}$ and $\mathrm{F}_{4}$ were replicated three times.

\section{Effects of subjecting nymphs to a double heat shock on the biological parameters of their offspring}

Experiments and rearing were conducted as above, except that the double heat shock was applied to second instar nymphs (Fig. S4).

\section{Effects of heat shock on ovaries}

One hundred 1-day-old second instar nymphs and 100 1-dayold adults (50 females and 50 males) were exposed to 41 and $45^{\circ} \mathrm{C}$, respectively, for $2 \mathrm{~h}$ as described above. Two control groups that were not subjected to a heat shock were also established. The survivors were collected and continuously maintained in bottles (ca. 90-100 individuals per bottle, with new food supplied every 3 days) until the emergence of adults of the $\mathrm{F}_{3}$ generation as described above. Twenty surviving adult females of the parental and each offspring generation were randomly collected 15 days (Ma et al., 2016) after emergence. Each female was dissected on a 

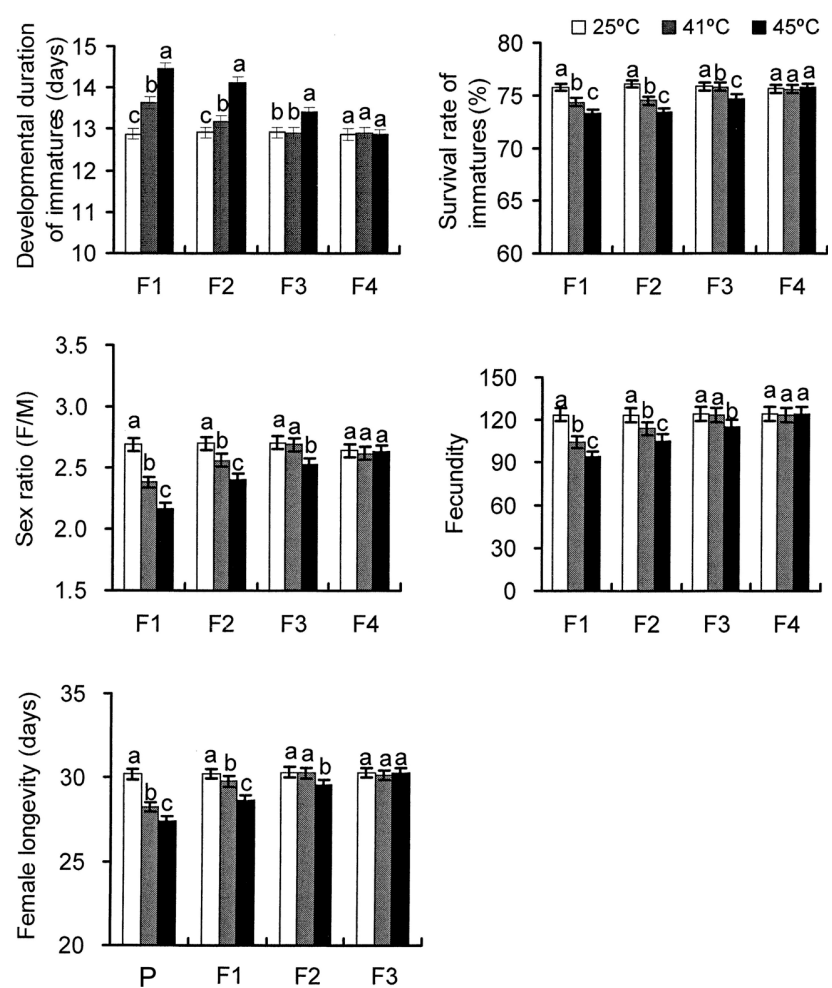

Fig. 1. Biological parameters (mean $\pm S D$ ) of the first $\left(F_{1}\right)$, second $\left(F_{2}\right)$, third $\left(F_{3}\right)$ and fourth $\left(F_{4}\right)$ generation offspring of adults of Frankliniella occidentalis subjected to a single heat shock (41 or $45^{\circ} \mathrm{C}$ for $2 \mathrm{~h}$ ). Data for $25^{\circ} \mathrm{C}$ are for the controls. Different letters indicate significant differences (Tukey test after ANOVA, $P<0.05$ ).

concave glass slide in phosphate buffered solution (pH 7.4) under a microscope (a patent is being applied for regarding the dissection method) to record the structure of the ovarioles. As a control, 20 adult females randomly selected from the control group were dissected (Fig. S5 for nymph; Fig. S6 for adult). The experiments involving heat treatment of the parental generation and examination of the ovarioles of the females of the parental and $F_{1}, F_{2}, F_{3}$ and $\mathrm{F}_{4}$ generations were replicated three times.

\section{Statistical analyses}

Data from the three replicates were used for calculating the means and standard deviations (SD) and statistical analyses. The data were analysed by one-way analysis of variance (ANOVA) followed by Tukey's post hoc test for more than two samples and Student's $t$-test for comparisons between two samples, in the SPSS 19.0 software package (Norman et al., 2010). The data including the survival of immature WFT, sex ratio and percentage with deformed ovaries were arcsine square root transformed to obtain normal distributions and homogeneity of variance before statistical analyses.

\section{RESULTS}

\section{Effects of a single heat shock on the biological parameters of the offspring}

The single heat shock of adults changed the biological parameters of the subsequent generations and had an adverse effect on their development and reproduction (Fig. 1). The duration of development of immature WFT was prolonged, and the survival of immature WFT, the sex ratio (female/male) and female fecundity and longevity decreased. The adverse effects on these parameters gradually
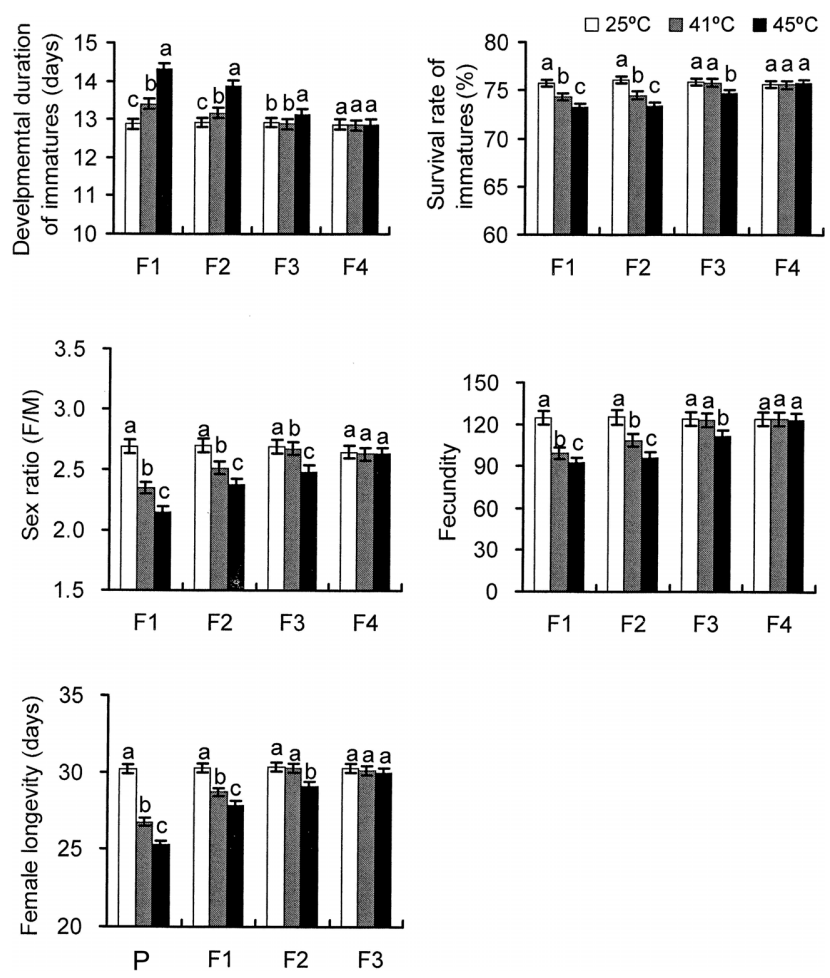

Fig. 2. Biological parameters (mean $\pm S D$ ) of the $F_{1}, F_{2}, F_{3}$ and $\mathrm{F}_{4}$ generation offspring of Frankliniella occidentalis that were subjected to a single heat shock ( 41 or $45^{\circ} \mathrm{C}$ for $2 \mathrm{~h}$ ) when they were second instar nymphs. Data for $25^{\circ} \mathrm{C}$ are for the controls. Different letters indicate significant differences (Tukey test after ANOVA, $P$ $<0.05)$.

weakened from generation to generation. The temperature of $45^{\circ} \mathrm{C}$ had a more severe effect than the temperature of $41^{\circ} \mathrm{C}$, and the effect of $45^{\circ} \mathrm{C}$ persisted for more generations than that of $41^{\circ} \mathrm{C}$ (Fig. 1).

Similar trends were recorded in the experiments in which the heat shock was applied to second instar nymphs of the parental generation; the thermal injury caused by $45^{\circ} \mathrm{C}$ was more pronounced than that caused by $41^{\circ} \mathrm{C}$, and the effects of $45^{\circ} \mathrm{C}$ persisted for more generations than that of $41^{\circ} \mathrm{C}$ (Fig. 2).

\section{Effects of a double heat shock on the biological parameters of the offspring}

Double heat shock applied to second instar nymphs and adults similarly had a more severe effect on the biological parameters of $\mathrm{F}_{2}$ progenies than a single heat shock (Figs 3 and 4).

\section{Effects of heat shock on ovariole structure}

Normally, WFT have a pair of ovaries, each of which is composed of four ovarioles (Ma et al., 2016). Heat shock treatment of second instar nymphs of the parental generation mainly resulted in the adults and their female offspring having fewer ovarioles (Fig. 5A), whilst heat shock treatment of adults of the parental generation mainly resulted in deformed ovarioles in treated females and their female offspring (Fig. 5B). In both cases, the higher temperature $\left(45^{\circ} \mathrm{C}\right)$ had a more pronounced effect than the lower tem- 

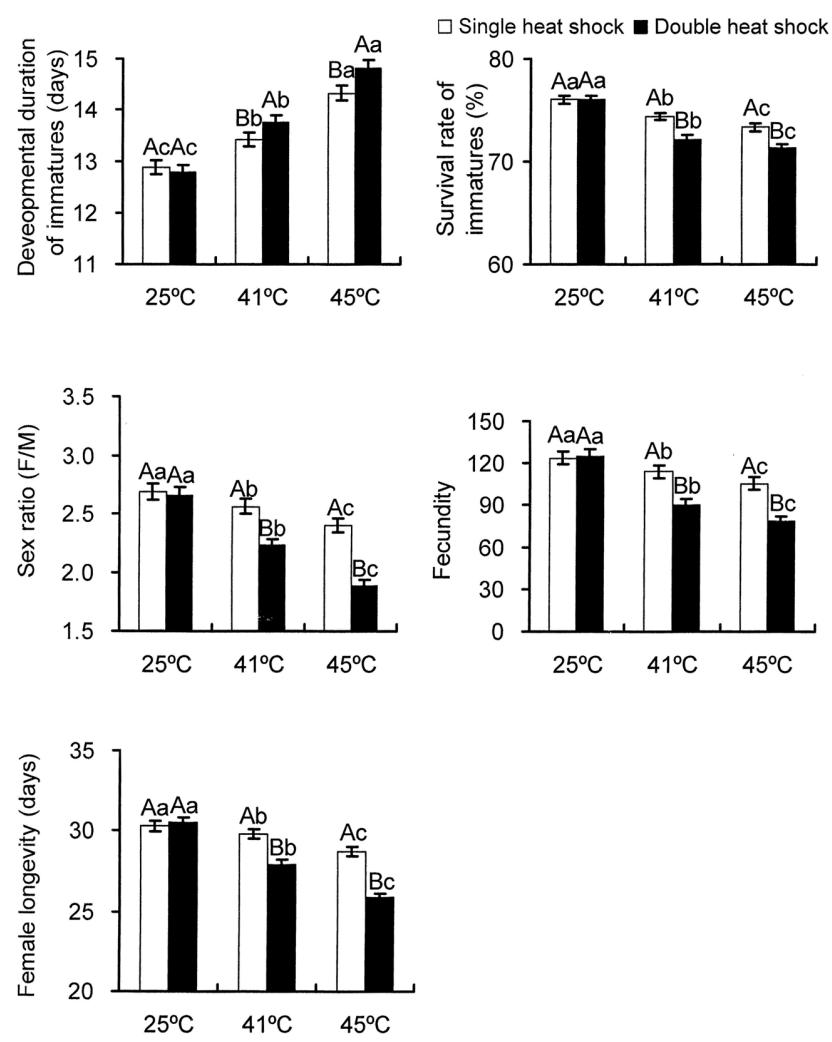

Fig. 3. Biological parameters (mean $\pm S D$ ) of the $F_{2}$ generation offspring of adults of Frankliniella occidentalis that were subjected to either a single or double heat shock $\left(41\right.$ or $45^{\circ} \mathrm{C}$ for $2 \mathrm{~h}$ ). Heat shock was applied only to the parental generation (single heat shock) or to the parental and $F_{1}$ generations (double heat shock). Data for $25^{\circ} \mathrm{C}$ are for the controls. Different uppercase letters indicate significant differences between single and double heat shock experiments ( $t$-test, $P<0.05$ ), and different lowercase letters indicate significant differences between treatments within single or double heat shock experiments (Tukey test after ANOVA, $P<0.05$ ).

perature $\left(41^{\circ} \mathrm{C}\right)$, and the effect became weaker from generation to generation (Fig. 5).

\section{DISCUSSION}

Insects are small ectotherms and temperature is one of the key abiotic factors influencing their survival, development, behaviour, life history, fitness, distribution and species richness (Denlinger \& Yocum, 1998; Rogers \& Randolph, 2000; Ma et al., 2004a, b). Within a certain temperature range, the growth, development and reproduction of insects increase with increase in temperature (Murai, 2000). However, when exposed to high or extremely high temperatures, the development of insects is retarded or they are killed (Denlinger \& Yocum, 1998; Rinehart et al., 2000). The effects of high temperature on development and reproduction have been studied in many insects, such as Helicoverpa armigera Hübner (Guo et al., 2000), Liriomyza huidobrensis (Blanchard) (Zhou et al., 2000), Aphis gossypii Glover (Zhou et al., 2002), Bemisia tabaci B-biotype (Wang \& Fan, 2003) and the present study species, Frankliniella occidentalis (Zhang et al., 2009). However, the maternal effects of high temperature treatments of the parental generation on their offspring are rarely studied. Moreover, when the maternal effects are studied, they are

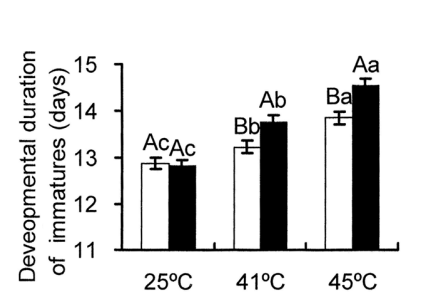

$\square$ Single heat shock $\square$ Double heat shocl
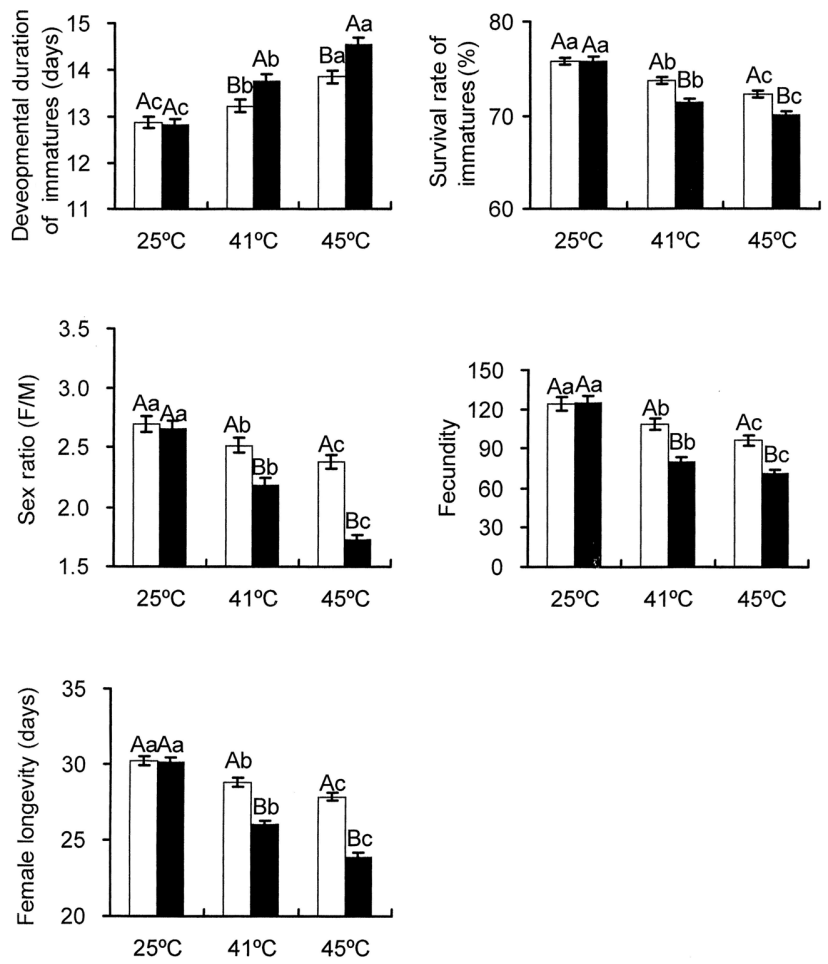

Fig. 4. Biological parameters (mean $\pm S D$ ) of the $F_{2}$ generation of Frankliniella occidentalis that were subjected to either a single or double heat shock ( 41 or $45^{\circ} \mathrm{C}$ for $2 \mathrm{~h}$ ) when they were second instar nymphs. Heat shock was applied only to the parental generation (single heat shock) or to the parental and $F_{1}$ generations (double heat shock). Data for $25^{\circ} \mathrm{C}$ are for the controls. Different uppercase letters indicate significant differences between single and double heat shock treatments ( $t$-test, $P<0.05$ ), and different lowercase letters indicate significant differences between treatments within the single or double heat shock experiments (Tukey test after ANOVA, $P<0.05$ ).
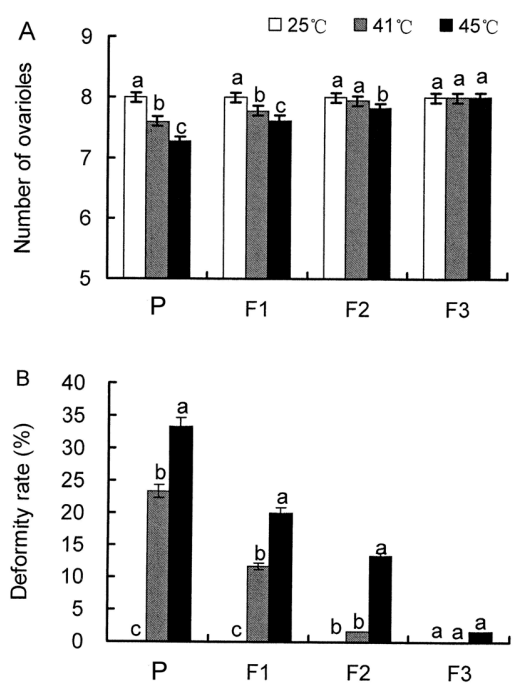

Fig. 5. (A) The number of ovarioles (mean $\pm S D$ ) in parental $(P)$, $\mathrm{F}_{1}, \mathrm{~F}_{2}$ and $\mathrm{F}_{3}$ females of Frankliniella occidentalis when the second instar nymphs of the parental generation were subjected to a single heat shock ( 41 or $45^{\circ} \mathrm{C}$ for $2 \mathrm{~h}$ ). (B) The percentage (mean $\pm \mathrm{SD}$ ) of $P, F_{1}, F_{2}$ and $F_{3}$ females that had deformed ovarioles when the adults of the parental generation were treated with a single heat shock ( 41 or $45^{\circ} \mathrm{C}$ for $2 \mathrm{~h}$ ) (B). Data for $25^{\circ} \mathrm{C}$ are for the controls. Different letters indicate significant differences (Tukey test after ANOVA, $P<0.05)$. 
only recorded for one or two generations. For example, the effects of maternal temperature on the morphology and physiology of Drosophila melanogaster was studied for only two generations (Crill et al., 1996), and the effects of a brief exposure to high temperature on bionomic parameters of the offspring of Bemisia tabaci Q-biotype are recorded for only one generation (Chen et al., 2011). In the present study on Frankliniella occidentalis, the effects of a single heat shock of 41 or $45^{\circ} \mathrm{C}$ persisted for more than two generations and a temperature treatment of $45^{\circ} \mathrm{C}$ had more severe effects and persisted for more generations than that of $41^{\circ} \mathrm{C}$. In addition, a double heat shock had a more severe effect than a single heat shock. These results should help to improve our understanding of the mechanism by which high temperature suppresses the growth of WFT populations.

In our study, the adults allowed to produce offspring were randomly selected from those actively moving in order to ensure they were viable. Therefore, the effects of the heat shock treatment in this study were maternal.

Thermal stress adversely affects the reproductive system and the mating behaviour of insects (Cui et al., 2008; Zhu et al., 2010). In this study, we found that heat shock treatment of nymphs resulted in a decrease in the number of ovarioles of the parental females and that of the females of the $F_{1}$ and $F_{2}$ generations. Similar results are reported for D. melanogaster (Audit \& Busson, 1981). However, heat shock treatment of adults resulted in deformed ovarioles, which is thought to be caused by inhibition of the synthesis, absorption and transport of vitellogenin (Wang et al., 2006; Ma et al., 2016).

Though the effects of high temperature are reported for a number of insects, the mechanism of inheritance of the effect of high temperature treatment is not well understood. Environmental stresses are reported to affect the regulation of germline genes through DNA methylation and inherited environmental effects can be responsible for apparently reversible mutations (Jablonka \& Lamb, 1989). Two novel heat shock protein 70s encoded by Fohsc704 and Fohsc705 were recently reported to play important roles in the thermal tolerance of $F$. occidentalis (Qin et al., 2018). To explore the maternal effects of high temperature on WFT, the regulation of genes such as Fohsc704 and Fohsc705, as well as DNA methylation, should be analysed in the offspring of heat shocked $F$. occidentalis in future studies.

ACKNOWLEDGEMENTS. This study was funded by the National Natural Science Foundation of China (31372003) and Shandong Modern Agricultural Technology and Industry System (STADIT-05-13).

\section{REFERENCES}

Andersen D.H.C., Pertoldi V., Scali V. \& Loeschcke V. 2005: Heat stress and age induced maternal effects on wing size and shape in parthenogenetic Drosophila mercatorum. - J. Evol. Biol. 18: 884-892.

Audit C. \& Busson D. 1981: Oogenesis defects in the ecd-1matant of Drosophila melanogaster, deficient in ecdysteroid at high temperature. - J. Insect Physiol. 27: 829-837.
Carroll D. \& Hoyt S. 1986: Some effects of parental rearing conditions and age on progeny birth weight, growth, development, and reproduction in the apple aphid, Aphis pomi (Homoptera: Aphididae). - Environ. Entomol. 15: 614-619.

Chen T., Guo J.Y. \& WANG F.H. 2011: Effects of heat shock temperature and duration on development and reproduction of $B e$ misia tabaci Q-biotype (Homoptera: Aleyrodidae). - Chin. J. Appl. Environ. Biol. 17: 398-403.

Crill W.D., Huey R.B. \& Gilchrist G.W. 1996: Within and between-generation effects of temperature on the morphology and physiology of Drosophila melanogaster. - Evolution 50: 1205-1218.

Cui X., Wan F.H., XiE M. \& LiU T. 2008: Effects of heat shock on survival and reproduction of two whitefly species, Trialeurodes vaporariorum and Bemisia tabaci biotype B. - J. Insect Sci. 8: $1-10$.

CuI X.H., Xu J.X., Li X.Y. \& CAI C. 2011: Effects of brief exposure to high temperature on survival and fecundity of Bemisia tabaci Q-biotype (Homoptera: Aleyrodidae). - Chin. Agric. Sci. Bull. 5: 377-379 [in Chinese].

Denlinger D.L. \& Yocum G.D. 1998: Physiology of heat sensitivity. In Hallman G.J. \& Denlinger D.L. (eds): Temperature Sensitivity: Insects and Application in Intergraded Pest Management, Westview Press, Boulder, CO, pp. 6-53.

Guo H.F., Chen C.K. \& Li G.Q. 2000: Influence of high temperature on male fecundity of cotton bollworm. - J. Nanjing Agric. Univ. 23: 30-33 [in Chinese].

JABLONKA E. \& LAMB M.J. 1989: The inheritance of acquired epigenetic variations. - J. Theor. Biol. 139: 69-84.

JiAng S., Zhang B., Wang S.F. \& Zheng C.Y. 2014: Effects of heat shock on Frankliniella occidentalis $\mathrm{F}_{1}$ offspring. - Fla Entomol. 97: 1157-1166.

Jiang S., Li S., Zhang B., Li H.G., Wan F.H. \& Zheng C.Y. 2016 : Effects of extreme high temperature on survival rate, reproduction, trehalose and sorbitol of Frankliniella occidentalis. Sci. Agric. Sin. 9: 2310-2321.

KIRK W.D.J. \& TERRY L. 2003: The spread of the western flower thrips Frankliniella occidentalis (Pergande). - Agric. Forest Entomol. 5: 301-310.

Ma C.S. \& Hau B. \& Poenling H.M. 2004a: Effects of pattern and timing of high temperature exposure on reproduction of the rose grain aphid, Metopolophium dirhodum. - Entomol. Exp. Appl. 110: 65-71.

Ma C.S., Hau B. \& Poehling H.M. 2004b: The effect of heat stress on the survival of the rose grain aphid, Metopolophium dirhodum (Hemiptera: Aphididae). — Eur. J. Entomol. 101: 327-332.

Ma Y.B., Sun L.J., Li H.G., WANG S.F., Zhang B. \& Zheng C.Y. 2016: Effects of high temperature on ovary development and yolk protein content of Frankliniella occidentalis (Thysanoptera: Thripidae). - Acta Entomol. Sin. 59: 127-137 [in Chinese].

MuRai T. 2000: Effect of temperature on development and reproduction of the onion thrips, Thrips tabaci Lindeman (Thysanoptera: Thripidae), on pollen and honey solution. - Appl. Entomol. Zool. 35: 499-504.

Norman H.N., Hull C. \& Dale H.B. 2010: IBM SPSS Statistics 19.0. Stanford University, Palo Alto, CA. URL: http:// www.33lc.com/soft/41991.html.

Qin J., Gao P., Zhang X.X., Lu M.X. \& Du Y. Z. 2018: Characterization of two novel heat shock protein 70 s and their transcriptional expression patterns in response to thermal stress in adult of Frankliniella occidentalis (Thysanoptera: Thripidae). —J. Interact. Agric. 17: 1023-1031. 
Rinehart J.P., Yocum G.D. \& Denlinger D.L. 2000: Thermotolerance and rapid cold hardening ameliorate the negative effects of brief exposures to high or low temperatures on fecundity in the flesh fly, Sarcophaga crassipalpis. - Physiol. Entomol. 25: $330-336$.

RoAch D.A. \& WulfF R.D. 1987: Maternal effects in plants. Annu. Rev. Ecol. Syst. 18: 209-223.

Rogers D.J. \& RANDOLPH S.E. 2000: The global spread of malaria in a future, warmer world. - Science 289: 1763-1766.

Van Rijn P.C.J., Mollema C. \& Steenhuis-Broers G.M. 1995: Comparative life history studies of Frankliniella occidentalis and Thrips tabaci (Thysanoptera: Thripidae) on cucumber. Bull. Entomol. Res. 85: 285-297.

WANG H.J. \& FAN H.J. 2003: Controlling Bemisia tabaci with high temperature in greenhouse. - Vegetable 10: 30-31 [in Chinese].

WANG F.S., Xu H.F. \& CuI F. 2006: Effect of high temperature on fecundity and ovary development of beet armyworm Spodoptera exigua. - Southw. China J. Agric. Sci. 19: 916-919 [in Chinese].

WANg J.C., Zhang B., Li H.G., Wang J.P. \& Zheng C.Y. 2014a: Effects of exposure to high temperature on Frankliniella occidentalis (Thysanoptera: Thripidae), under arrhenotoky and sexual reproduction condition. - Fla Entomol. 97: 504-510.

Wang J.C., Zhang B., Li H.G., Wang J.P. \& Zheng C.Y. 2014b: Effects of heat stress on survival of Frankliniella occidentalis (Thysanoptera: Thripidae) and Thrips tabaci (Thysanoptera: Thripidae). - J. Econ. Entomol. 107: 1426-1433.
Zhang Y.J., Wu Q.J., XU B.Y. \& ZHU G.R. 2003: The occurrence and damage of Frankliniella occidentalis (Thysanoptera: Thripidae): a dangerous alien invasive pest in Beijing. — Plant Prot. 4: 58-59 [in Chinese].

Zhang L.F., Ding Y.M., Chen A.D., Qu S.P. \& Wang J.H. 2009: Preliminary study of lethal effect of high temperature on the Frankliniella occidentalis. - North. Hortic. 2: 115-116 [in Chinese].

Zheng C.Y., LiU Y.H. \& ZHANG N.Q. 2007: Invasive insect pest Frankliniella occidentalis first reported in Shandong provinc. - J. Qingdao Agric. Univ. (Nat. Sci.) 24: 172-174 [in Chinese].

Zhou Y.H., Zhaо Z.M., Deng X.P. \& Wu S.Y. 2000: Effect of temperature on the population of Liriomyza huidobrensis (Blanchard). - J. Nanjing Agric. Univ. 23: 33-36 [in Chinese].

Zhou Q., Liang G.W. \& Cen Y.J. 2002: The influence of temperature and host plants on the experimental population of Aphis gossypii Glover. - J. South China Agric. Univ. 23: 31-37 [in Chinese].

Zhu S.G., Li Z.H. \& WaN F.H. 2010: Effects of brief exposure to high temperature on survival and reproductive adaptation of Bemisia tabaci Q-biotype. - Chin. Bull. Entomol. 47: 1141-1144 [in Chinese].

Received January 9, 2019; revised and accepted May 10, 2019 Published online June 26, 2019

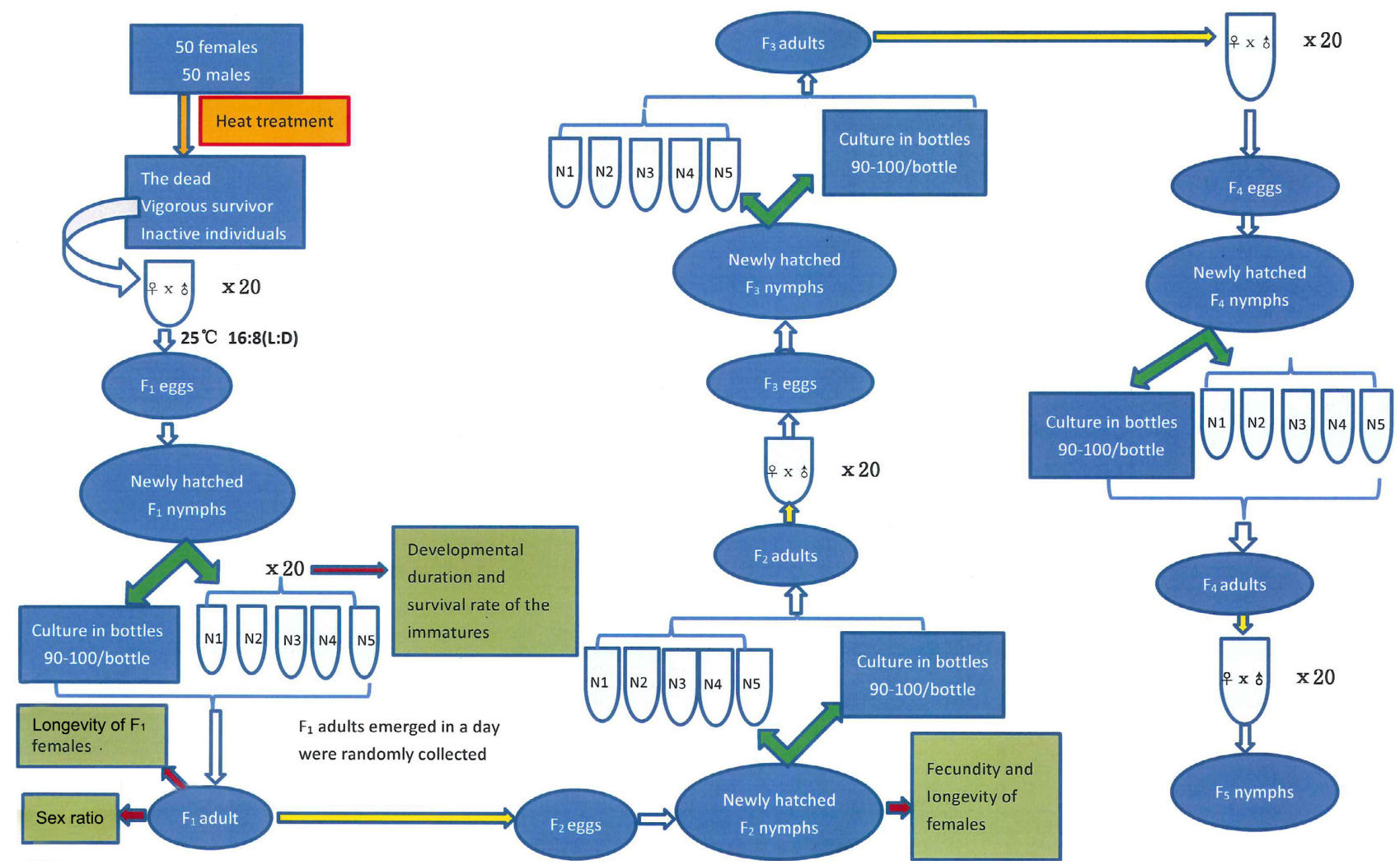

Fig. S1. Schemes of experimental design for a single heat shock treatment to parental adults $\left(41\right.$ or $45^{\circ} \mathrm{C}$ for $\left.2 \mathrm{~h}\right)$. 


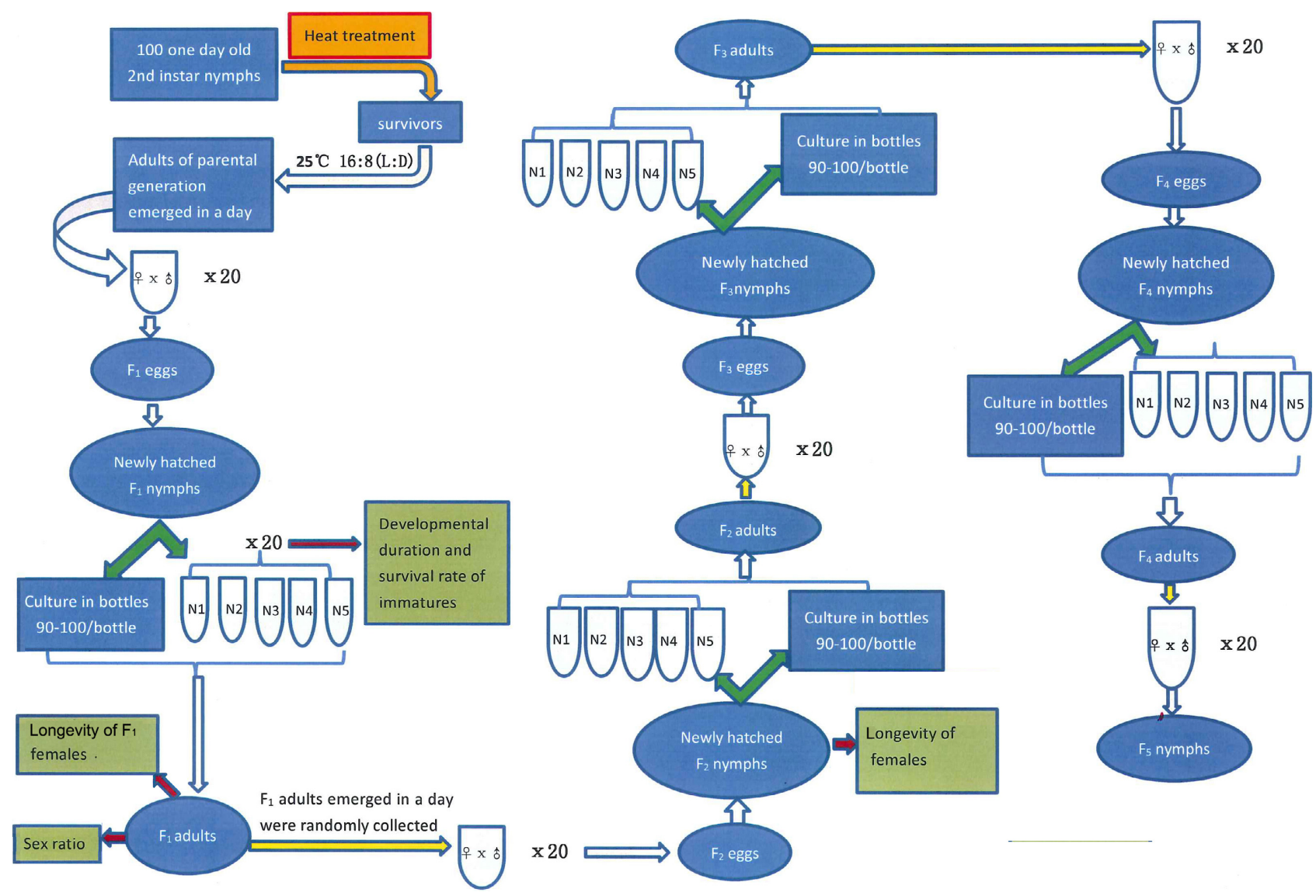

Fig. S2. Schemes of experimental design for a single heat shock treatment to parental second instar nymphs $\left(41\right.$ or $45^{\circ} \mathrm{C}$ for $\left.2 \mathrm{~h}\right)$.

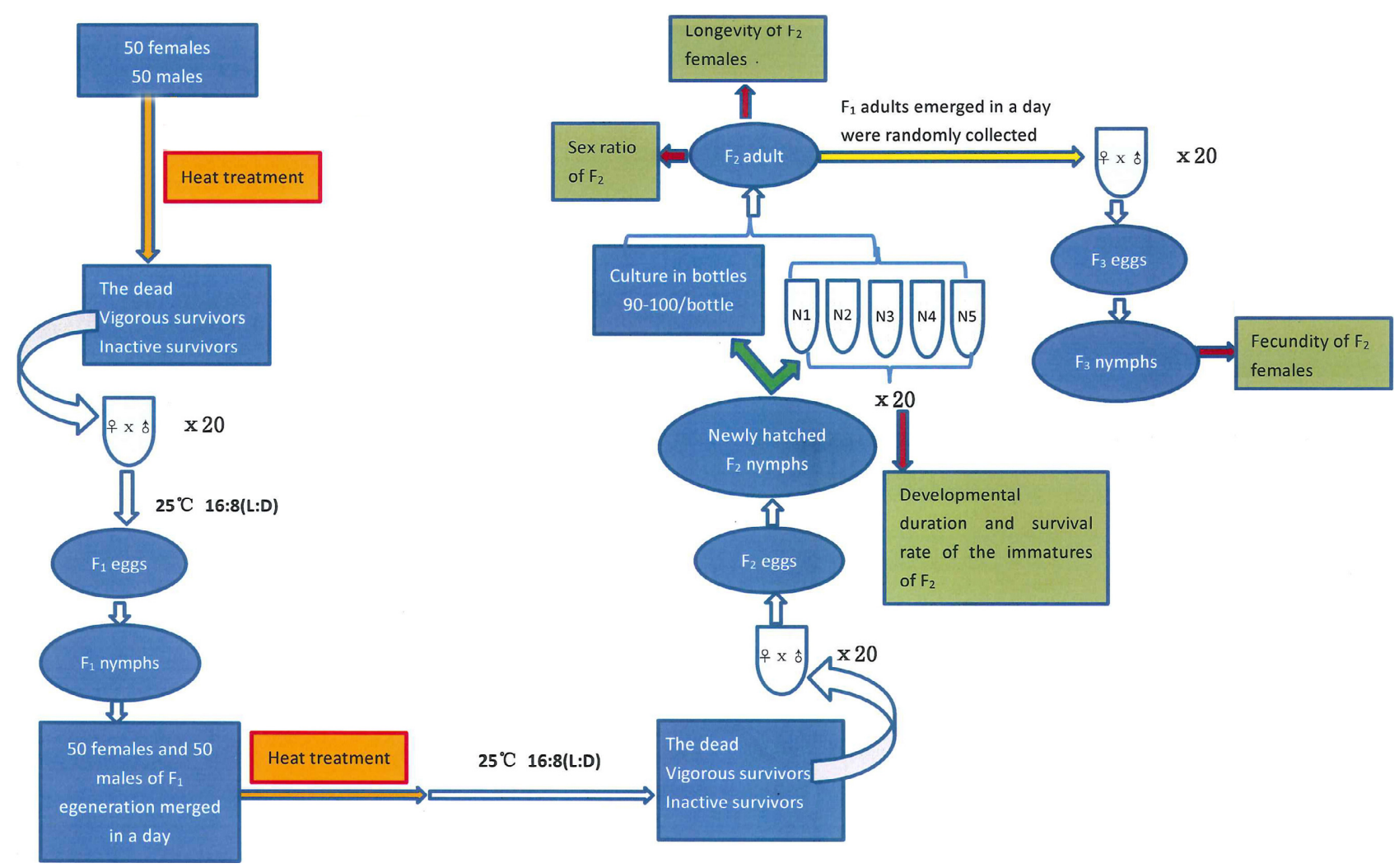

Fig. S3. Schemes of experimental design for a double heat shock treatment to parental adults $\left(41\right.$ or $45^{\circ} \mathrm{C}$ for $\left.2 \mathrm{~h}\right)$. 




Fig. S4. Schemes of experimental design for a double heat shock treatment to parental second instar nymphs $\left(41\right.$ or $45^{\circ} \mathrm{C}$ for $\left.2 \mathrm{~h}\right)$.

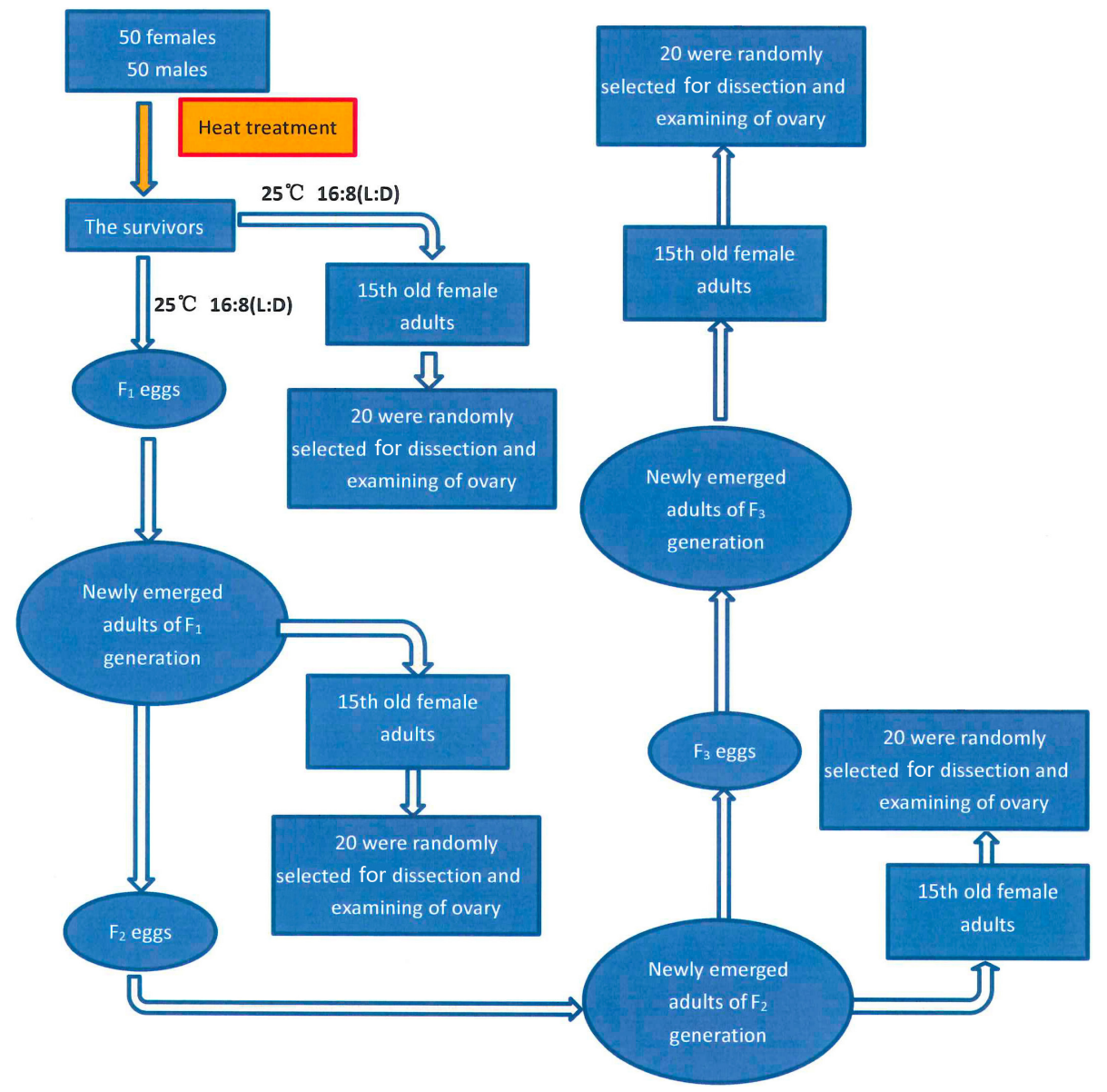

Fig. S5. Schemes of experimental design for effect of heat shock to ovary (the parental second instar nymphs were subjected to a single heat shock at 41 or $45^{\circ} \mathrm{C}$ for $2 \mathrm{~h}$ ). 


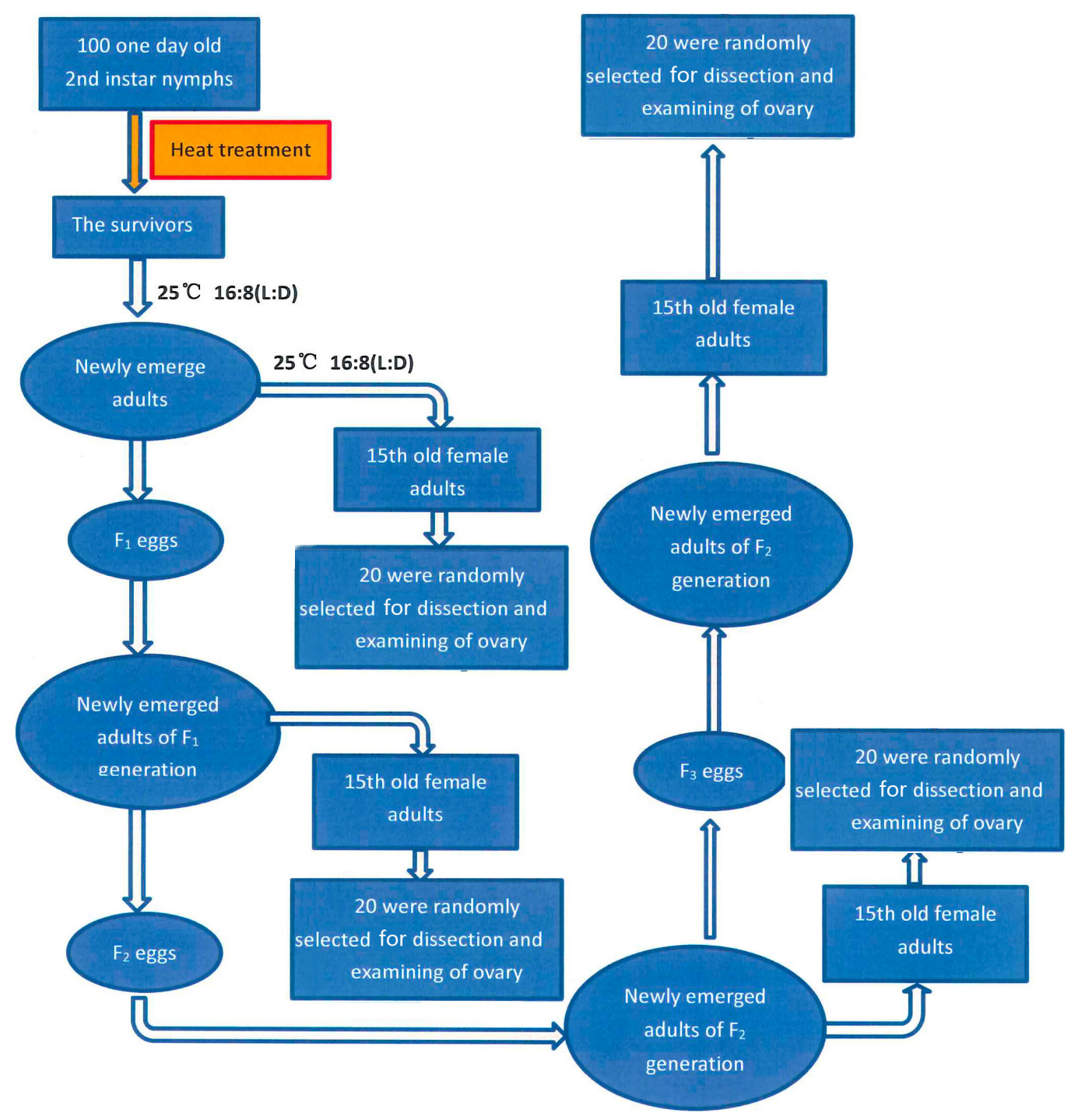

Fig. S6. Schemes of experimental design for effect of heat shock to ovary (the parental adults were treated with a single heat shock at 41 or $45^{\circ} \mathrm{C}$ for $2 \mathrm{~h}$ ). 